\title{
Investigating MOOCs Through Blog Mining
}

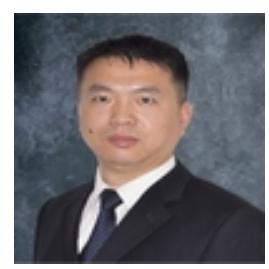

Yong Chen

Old Dominion University, USA

\section{Abstract}

MOOCs (massive open online course) is a disruptive innovation and a current buzzword in higher education. However, the discussion of MOOCs is disparate, fragmented, and distributed among different outlets. Systematic, extensively published research on MOOCs is unavailable. This paper adopts a novel method called blog mining to analyze MOOCs. The findings indicate, while MOOCs have benefitted learners, providers, and faculty who develop and teach MOOCs, challenges still exist, such as questionable course quality, high dropout rate, unavailable course credits, ineffective assessments, complex copyright, and limited hardware. Future research should explore the position of MOOCs and how it can be sustained.

Keywords: MOOC; MOOCs; online learning; blog mining 


\section{Introduction}

A MOOC (massive open online course) is "an online course with the option of free and open registration, a publicly shared curriculum, and open-ended outcomes" (McAulay, Stewart, \& Siemens, 2010). As one of the two most emerging developments in educational technology, MOOC and tablet computing (New Media Horizon, 2013), MOOCs is the buzzword of 2012 in higher education (Daniel, 2012). The fast development of MOOCs attracts many reports and debates among educators. So far, a large volume of press articles and blogs has covered MOOCs. However, discussions of MOOCs are disparate, fragmented, and distributed among different outlets. Systematic and extensive published research on MOOCs is still unavailable (Daniel, 2012; Clow, 2013).

Since blog posts are the main sources of discussion about MOOCs at this stage, this paper adopts a novel research method, called blog mining, to analyze what themes and trends about MOOCs can be found. The goal of this research is to synthesize related discussions in blogs, to provide an in-depth review of MOOCs, and to identify the challenges and future trends of MOOCs. This paper hopes to aid MOOC providers and higher education institutions that might be interested in joining MOOCs to understand what is going on in this fast-moving field. It will offer necessary insights and tips so stakeholders can become knowledgeable about what drives the rapid expansion of MOOCs and the issues they are facing.

\section{Background}

In an age of global competition, information glut and rapid technological changes require learners to become informed on how to retrieve, organize, and evaluate information, how to construct knowledge, and how to develop the ability to work in teams (Mioduser, Nachmias, \& Forkush-Baruch, 2008; Schrire \& Levy, 2012). Due to the advance of information communication technologies (ICTs), the quality of online delivery platforms has improved in recent years. Online activities closely related to social media, such as discussions, blogs, and video lectures, can be easily embedded in online learning (Skiba, 2012). As an extension of existing online learning approaches (Yuan, Powell, \& Cetis, 2013), MOOCs is a model to deliver learning content of a course online to anyone who wants to take it (Educause, 2013). By taking advantage of various web-based technologies, including video presentations, computer-based assessments, and online communication forums, MOOCs allows a large number of learners to access course content, formative and summative assessments, and supports from their fellow learners (Balfour, 2013). It is "a dynamic learning model that offers collaborative and social engagement opportunities for learners to construct knowledge" (Skiba, 2012, p. 416). MOOCs is self-organizing, connected, and open. It has embedded social media affordances, such as perpetual connectivity, asynchronous interaction, unforeseen 
collaborations, and emerging learning opportunities (deWaard, Abajian, Gallagher, Hogue, Keskin, Koutropoulos, \&Rodriguez, 2011).

In 2008, Siemens and Downes offered the first MOOC - " Connectivism and Connective Knowledge" (Yuan, Powell, \& Cetis, 2013). This is a type of asynchronous online learning, which can involve a large number of learners and flexibility for different levels of learners. What makes it unique is that it is free and open to anyone who has Internet access. The creators believed a free course could bring the best education in the world to the most remote corners of the planet, help people in their careers, and expand intellectual and personal networks (Pappano, 2012). This belief seems to be proven by a MOOC called "artificial-intelligence", launched by a Stanford professor, Sebastian Thrun, in 2011, which attracted 160,000 learners in 190 countries (Lewin, 2012). Since MOOCs has been booming in recent years, it plays an increasingly important role in higher education around the world (Meyer \& Zhu, 2013).

MOOCs represents an emerging methodology of online teaching and an important development in open education. Its structure was inspired by the philosophy of connectivism and implementation requires conceptual changes in perspectives from both facilitators (tutors) and learners (Rodriguez, 2013). It is "based on the explicit principles of connectivism (autonomy, diversity, openness, and interactivity) and on the activities of aggregation, remixing, repurposing and feeding forward the resources and learning" (Rodriguez, 2013, p. 1). MOOCs has two distinct branches: (1) connectivist MOOCs (cMOOCs) and (2) a more formal MOOCs (xMOOCs) (Hill, 2012). The pedagogies behind these two branches are different. cMOOCs is built on connectivism (Kop \& Hill, 2008; Siemens \& Downes, 2008), which is a sophisticated and innovative reconceptualization of what it means to know and to learn. In contrast, xMOOCs is based on behaviorist pedagogy that relies on information transmission (Bates, 2012). Siemens (2012) notes, "CMOOCs focus on knowledge creation and generation whereas xMOOCs focus on knowledge duplication" (p. 1). According to Rodriguez (2013), learners and their knowledge are the focuses of cMOOCs. He points out that successful cMOOCs examples in recent years include Connectivism and Connective Knowledge (CCK08), Personal Learning Environments, Networks, and Knowledge (PLENK2010), MobiMOOC (2010), EduMOOC (2011), Change11 (2011/2012), Digital Story Telling (DS106) (2011/2012), and LAK12 (2012). However, compared with cMOOCs, xMOOCs attracts more attention. It focuses on the course content or the instructor. The main players in xMOOCs are Coursera, Udacity, EdX, MITx, and Udemy. Table 1 provides brief descriptions of them. 
Table 1

Main xMOOCs

\begin{tabular}{|l|l|l|l|l|}
\hline Initiatives & Introduction & For profit & $\begin{array}{l}\text { Certification } \\
\text { fee }\end{array}$ & $\begin{array}{l}\text { Institution } \\
\text { credits }\end{array}$ \\
\hline Coursera & $\begin{array}{l}\text { An educational company } \\
\text { founded by two Stanford } \\
\text { professors in April 2012. }\end{array}$ & Yes & Yes & Partially \\
\hline Udacity & $\begin{array}{l}\text { A start-up founded by Stanford } \\
\text { professors offering free courses } \\
\text { in partnership with colleges } \\
\text { and professors. }\end{array}$ & Yes & Yes & Partially \\
\hline edX & $\begin{array}{l}\text { A joint partnership between } \\
\text { Massachusetts Institute of } \\
\text { Technology (MIT) and Harvard } \\
\text { in December 2011. }\end{array}$ & No & Yes & No \\
\hline Udemy & $\begin{array}{l}\text { A learning platform founded by } \\
\text { investors. }\end{array}$ & Yes & Yes & Partially \\
\hline
\end{tabular}

(Source: Yuan, Powell, \& Cetis, 2013)

MOOCs is the current buzzword in higher education. Because it is a disruptive innovation (Skiba, 2012), it initiates many discussions about higher education. Although its future is not clear yet, a number of MOOC platforms have been developed and offer courses independent of or in collaboration with universities (Yuan, Powell, \& Cetis, 2013). In 2012, some elite universities lined up to join forces with MOOC providers (Lewin, 2012). For example, Coursera began with Princeton, the University of Pennsylvania, Stanford, and the University of Michigan. The University of California, Berkeley, and the University of Texas joined edX (Lewin, 2012). Despite the fast development of MOOCs, limited research or evidence is available to support either the positive or the negative opinions about them (Skiba, 2012).

\section{Method}

MOOCs is an innovative way of teaching and learning (Meyer \& Zhu, 2013). As a new type of asynchronous online learning, it provides unique benefits for learners and providers, namely higher education institutions, commercial organizations, and faculty. Because MOOCs is based on the Internet and blog posts are the main sources of discussions about it at this stage, a novel research method, blog mining, was employed in this study to synthesize the related discussions in blogs, to provide an in-depth review of MOOCs, and to identify the future trends and challenges of MOOCs. Blogs allow selfmotivated bloggers to freely and easily post ideas, individual experiences, and opinions (Furukawa, Ishizuka, Matsuo, Ohmukai, \& Uchiyama, 2007; Rubin, Burkel, \& QuanHaase, 2011). Since blogs have a "high degree of exophoricity, quotation, brevity, and rapid of content update" (Ulicny, Baclawski, \& Magnus, 2007, p. 1), running a blog 
mining analysis can improve the timeliness and relevance of this study (Chau \& $\mathrm{Xu}$, 2012). Figure 1 shows the steps of a blog mining process.

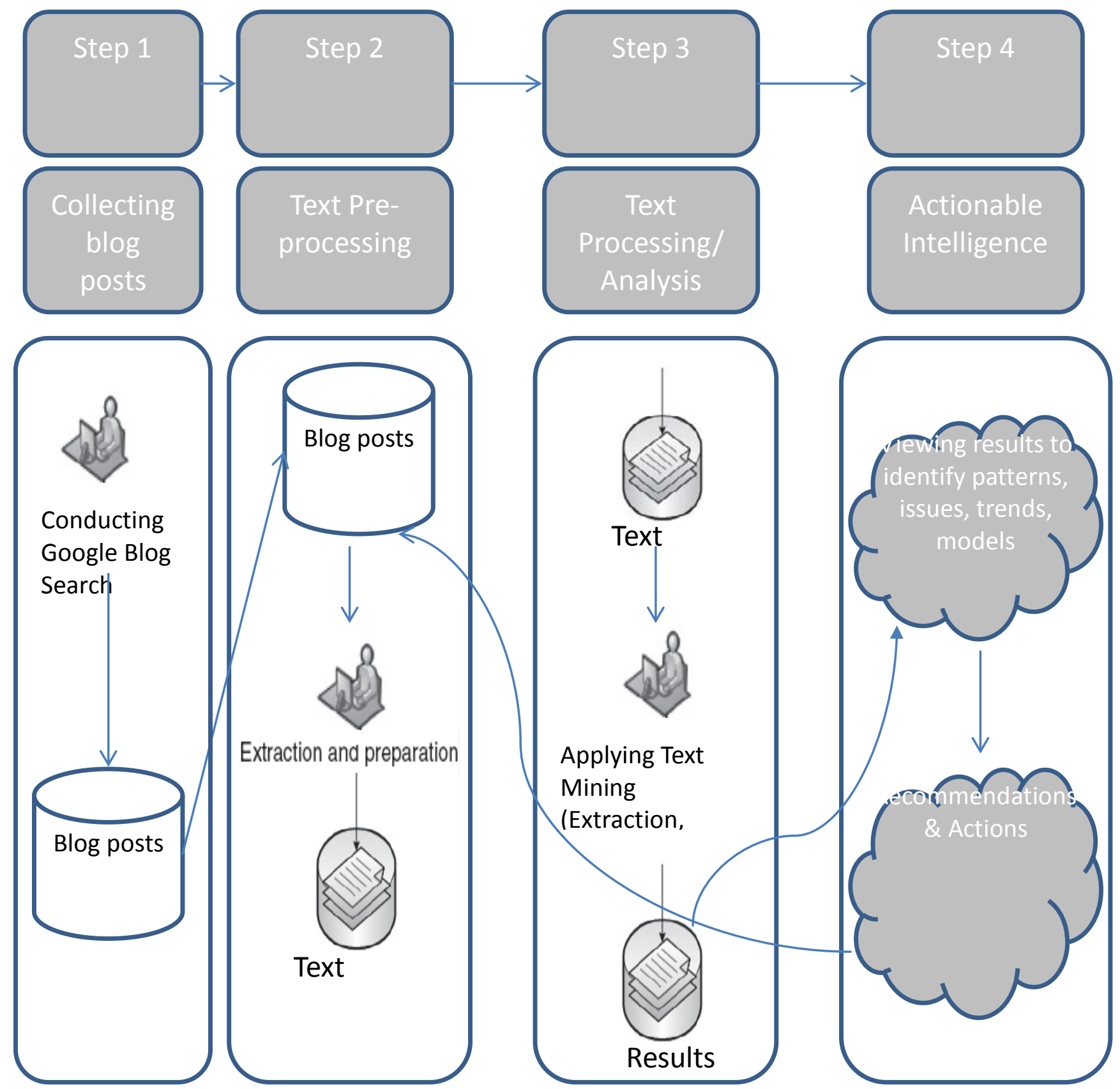

Figure 1. Blog mining process (Source: Abdous \& He, 2011).

Google Blog Search (http://www.google.com/blogsearch) is specially designed to retrieve content from blogs that are freely and publicly available on the Internet. In this study, a query search was conducted first by applying the advanced search option of Google Blog Search with the keyword "MOOC". To identify the latest blog content discussing MOOCs, the query time period was set from January 1, 2010 to J une 31, 
2013. After the query was performed, Google returned the results of the query search with a large number of blog posts created by numerous Internet bloggers. A further step-by-step examination of the resulting pages determined Google actually displayed 306 relevant blog posts and automatically filtered other blog posts considered very similar to the first 306 blog posts.

The blog posts were manually copied and saved as a text file for further analysis. Data pre-processing was conducted next via manually going through all the blog posts. This process determined five irrelevant or redundant blog posts for removal. The remaining posts were utilized as a finalized sample data set that provided a glimpse into the ongoing concerns and discussions associated with MOOCs. In the next step, a concept analysis and mapping (CAAM) technique was adopted to analyze the content of the remaining blog posts, because CAAM has been proven an effective research technique for studying textual written statements (Jackson \& Trochim, 2002). In particular, CAAM software called Leximancer (www.leximancer.com) was utilized to load the blog content, to extract and classify the key concepts and themes, and to identify the patterns and relationships between concepts and themes. Leximancer is

text mining software that can be used to analyze the content of collections of textual documents and to visually display the extracted information in a browser. The information is displayed by means of a conceptual map that provides an overview of the material, representing the main concepts contained within the text and how they are related. (Leximancer, 2010, p. 1)

Leximancer is based on Bayesian theory, which argues fragmented information can be used to predict what occurs in a system (Watson, Smith, \& Watter, 2005). In recent years, various studies have adopted Leximancer as their research tool (e.g., Watson, Smith, \& Watter, 2005; Smith \& Humphreys, 2006; Cretchley, Rooney, \& Gallois, 2010).

Leximancer looked for words that appeared most frequently in the loaded data and then generated a list of concepts. These concept terms were further clustered into themes, based on their relationship to each other. Next, clusters of concepts were grouped by themes named after the most prominent concept in that group. The themes were displayed as large circles on a concept map, which represented the strength of association between concepts and provided a conceptual overview of the semantic structure of the data (Cretchley, Rooney, \&Gallois, 2010; Martin \& Rice, 2011). Concept terms were displayed as spots in the large circles. The large theme circles were heatmapped to indicate their importance. For example, the most important theme appeared in red and the second hottest in orange and so on, according to the color wheel (Leximancer Manual, 2011). 


\section{Results}

Leximancer produced several types of concept maps that indicated the extracted concepts from the sample data set and their interrelationships. An example of concept maps generated by Leximancer from the sample data is shown in Figure 2. Leximancer generated a report that listed the themes and concept terms using its text analytics algorithms. Several closely linked concepts form a cluster and are displayed as dots inside circles. The closer the distance between concepts, the stronger they are semantically linked. Themes (clusters of concepts) are represented as circles. Their importance levels are indicated by the size and the heat degree color of the circles (Leximancer, 2010; Campbell, Pitt, Parent, \& Berthon, 2011; Martin \& Rice, 2011).

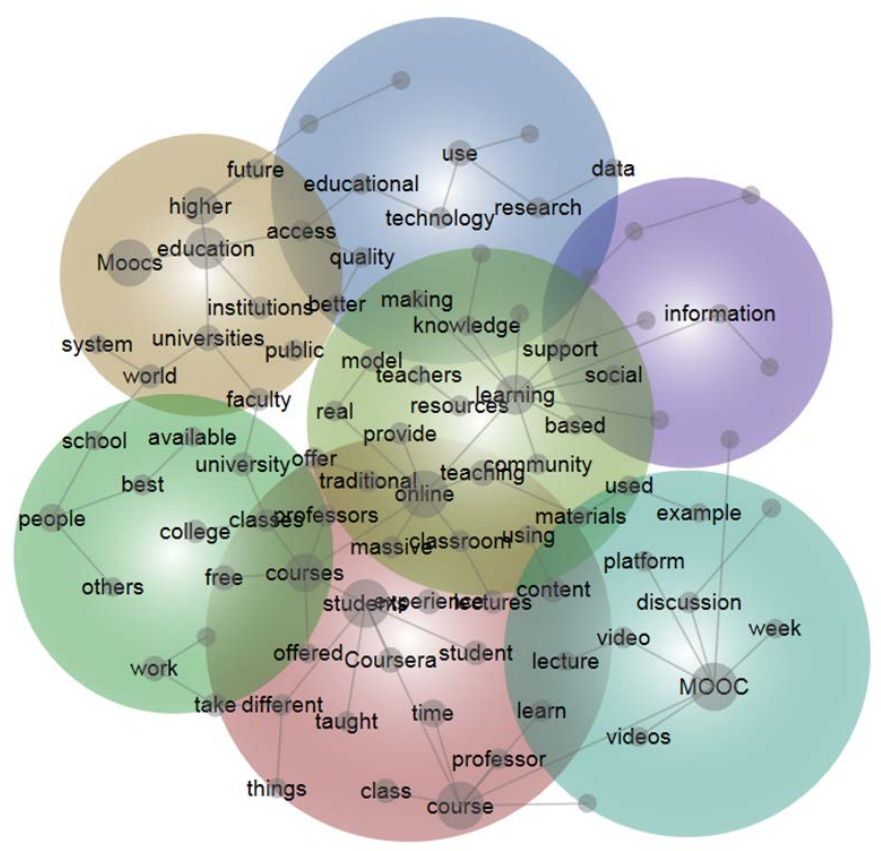

Figure 2. A concept map example generated by Leximancer from the sample data.

To better explain Figure 2, Table 2 lists each theme and the details of its concept terms. Themes are related with circles in Figure 2, while concept terms are related with the dots. 
Table 2

Cluster of Concepts Associated with MOOCs in Blog Posts

\begin{tabular}{|c|c|}
\hline $\begin{array}{c}\text { Cluster of concepts } \\
\text { (themes) }\end{array}$ & Concept terms \\
\hline Students & $\begin{array}{c}\text { Students, course, online, courses, time, Coursera, } \\
\text { content, experience, student, class, lectures, } \\
\text { professors, massive, learn, classroom, different, } \\
\text { professor, things, taught, offered }\end{array}$ \\
\hline MOOCs & $\begin{array}{c}\text { MOOCs, education, higher, universities, world, } \\
\text { faculty, institutions, access, public, better, future, } \\
\text { system }\end{array}$ \\
\hline Learning & $\begin{array}{c}\text { Learning, teaching, model, traditional, provide, offer, } \\
\text { community, resources, support, using, real, } \\
\text { materials, knowledge, used, social, based, } \\
\text { teachers }\end{array}$ \\
\hline People & $\begin{array}{c}\text { People, work, free, university, take, college, classes, } \\
\text { best, available, school, others }\end{array}$ \\
\hline MOOC & MOOC, video, discussion, platform, videos, lecture, \\
week, example
\end{tabular}

Surprisingly, MOOC and MOOCs are both themes. The differences between the concept terms in the two themes are shown in Table 2. Literally speaking, MOOC means a single mass open online course, while MOOCs are several such courses. However, according to the concept list generated by Leximancer in this study, MOOC refers to the structure and components of a mass open online course; whereas, MOOCs represent a new mode of higher education. The difference indicates bloggers have assigned specific meanings to MOOC and MOOCs in their posts.

\section{Discussion}

Compared with traditional classroom-based learning, MOOCs is an innovative way of teaching and learning (Meyer \& Zhu, 2013). This blog mining shows a number of elite higher education institutions around the world have provided MOOCs. Although the trend is unclear, MOOCs has brought big impacts to higher education. A detailed discussion is presented next. 


\section{Benefits for Learners}

Table 2 shows students and people are both themes in the blog mining results. As a disruptive innovation, MOOCs provides learners with a lot of benefits. MOOCs is open to any person who has access to the Internet. It provides free online courses and makes higher education accessible to a global audience (Meyer \& Zhu, 2013). Learners around the world can enroll in MOOCs without any cost. They can even take courses from top universities, as more elite higher education institutions provide MOOCs (Lewin, 2012). They do not need to go to campus or pay expensive tuition for taking courses from top ranking universities. This is a great benefit for learners in developing countries, where high quality, higher education resources are limited. Even in developed countries, MOOCs allows middle class families to offset their high college tuition rates (Thrift, 2013).

MOOCs is a great mechanism for lifelong learning (Skiba, 2012), and users range from teenagers to retirees (Pappano, 2012). According to Belanger and Thornton (2013), learners take MOOCs for the purpose of gaining an understanding of the subject matter, increasing social experience and intellectual stimulation, taking advantage of the convenience,overcoming barriers to traditional education options, and exploring online education. MOOCs is the right learning mode for people looking for extra learning by maximizing their time. This allows self-motivated learners to craft their own educational path by accessing the knowledge, lectures, quizzes, homework, exams, and personalities of the best professors at the top universities in the world (Raza, 2013).

Even in-class students can benefit from the online materials in MOOCs. In some MOOCs, in-class students and MOOC students take classes together. Some professors rearrange their courses to allow their students to complete the online lessons first and come to class later for interactive projects (Lewin, 2013). Such an arrangement allows in-class students and MOOC students to interact with each other. The interaction is very helpful for improving learning effects.

\section{Benefits for Providers}

MOOCs makes it possible for everyone to access higher education, so it has generated significant interest from policy-makers, higher education institutions, and commercial organizations (Yuan, Powell, \& Cetis, 2013). Carey (2013) argues that MOOCs helps higher education policy-makers to address budget constraint problems and to lower the cost of degree courses by experimenting with inexpensive, low-risk, higher education forms. Institutions have been involved in engaging and experimenting with MOOCs to expand access to higher education, achieve marketing and branding, and develop potential new revenue streams (Yuan, Powell, \& Cetis, 2013). Commercial organizations provide a platform based on MOOCs and develop partnerships with institutions to enter the higher education market and to explore new delivery modes in higher education (Yuan, Powell, \& Cetis, 2013). 
Other than the above stakeholders, faculty who teach MOOCs should not be neglected. MOOCs may be prompting some faculty to pay more attention to their teaching styles. It provides faculty an opportunity to learn from dedicated and successful teachers and re-examine their own pedagogical practices so that they can maintain or improve high quality interactions between themselves and students, in face-to-face courses and online courses. As Bali (2013) points out, faculty should dip into MOOCs for professional development, because MOOCs allows them to "observe how others teach online, join community conversations about topics that interest them, taste students' online learning experiences, learn something new in a structured way, and find well-chosen resources on a topic or sub-topic". Moreover, according to Kolowich (2013), MOOCs could increase faculty's visibility among their colleagues and with the general public, increase their earning power, and help them obtain tenure.

\section{Challenges}

In online learning, three characteristics are the most important: (1) quality of material covered, (2) engagement of the teacher, and (3) interactions among students (Pappano, 2012). Because MOOCs is an extension of existing online learning approaches (Yuan, Powell, \& Cetis, 2013), these three characteristics are highly important for MOOCs as well. Although a number of prestigious universities and commercial organizations have been involved in MOOCs and a large number of learners are taking MOOCs currently, MOOCs is confronted with a series of challenges regarding these three characteristics, such as questionable course quality, high dropout rate, unavailable course credits, limited learning assessment methods, puzzling copyright, and limited hardware.

\section{Questionable course quality.}

As mentioned above, the elite universities are rushing into MOOCs for the purpose of expanding access to higher education, marketing and branding, and developing new revenue streams. Are the MOOC courses they provide of good quality? Maybe some are not. As Daniel (2012) argues, even though the elite universities actively involved in MOOCs gained their reputations in research, they may or may not be talented in teaching, especially teaching online. In other words, research is different from teaching. That these elite universities make great achievements in research does not mean that they are capable of offering high quality online learning courses.

Another concern comes from the resources used to support the quality of MOOCs. High quality MOOC courses need huge investments. However, according to Yuan, Powell, and Cetis (2013), it is unclear how MOOCs will make money now and in the near future. For now, learners do not need to pay any fee for taking MOOC courses. But they must pay some fees for providers if they need certificates. Are these charges enough for providers to develop and maintain the academic rigor of MOOC courses the same as that of traditional classes, if not higher? Probably not. Without necessary investments, how can MOOCs with acceptable quality be produced continuously? 
Moreover, the huge number of learners in MOOCs causes big troubles for the interaction between instructors and learners. Usually social media is used widely by MOOCs for learner discussions. Since the number of learners in one single MOOC course is large, it is very difficult, maybe impossible, for the instructor to monitor all course discussions, interact with each learner, and provide feedback (Pappano, 2012; Clow, 2013). The lack of interaction between MOOC instructors and learners will definitely damage the course quality. In addition, the diversity of learners in a MOOC causes the lack of a common knowledge base and educational background among them (Pappano, 2012). As such, when learners post discussions about the course content or other related topics, these discussions might not be very fruitful. Because fruitful discussions are important components in the learning process, learners will not benefit much from such discussions. As a result, the course quality will be damaged by the lack of a common knowledge base and educational background among MOOClearners.

\section{High dropout rate.}

MOOCs has substantially higher dropout rates than traditional education (Clow, 2013). Only about $10 \%$ of the learners who enroll in the largest MOOCs actually complete the course (Daniel, 2012; Sandeen, 2013). Scholars have tried to determine the reasons. For example, Clow (2013) adopts the funnel of participation to explain the high dropout rates in MOOCs. He borrows the idea of "purchase funnel" from the field of marketing and sales, and separates learners' experiences in MOOCs into four steps: (1) awareness, (2) registration, (3) activity, and (4) progress. The number of learners in these steps becomes smaller and smaller from a MOOC's beginning to its end. Clow (2013) argues the high rate is difficult to mitigate because of a lack of existing support resources for learners. McAulay, Stewart, and Siemens (2010) note the high dropout rate is an almost-inevitable consequence of any open, online activity, because initial commitment is missing.

The high dropout rate in MOOCs might be caused by the low cost from the learners' side. Unlike traditional education, MOOCs does not require learners to pay tuition. Any learner can register for a MOOC without considering the cost. Thus, it is no wonder big registration numbers of many MOOCs are shown. In contrast, traditional education has limited space. Students must pay tuition to enroll in a course. They must think about the cost of dropping a course, because they will lose their money and probably need to pay the tuition again if they want to retake this course to obtain credit in the future. However, the cost for MOOCs learners to drop a course can be neglected. The dropping cost is so low that few learners will think about it seriously.

Another reason for the high dropout rate in MOOCs might be the lack of an admission process. No admission process makes MOOCs open to anyone. Learners can register a MOOC regardless of their educational background. Without the admission process, it is difficult to determine whether a learner's education background meets the requirements of a course and whether a course is right for a learner. Because the selection process is missing at the beginning, a big number of learners can register for a MOOC. Once the 
course begins, it is very likely some learners find the course is not what they want or their background does not allow them to catch up with the course.

\section{Unavailable course credits.}

Few colleges or universities offer full course credit to students who complete a MOOC (Meyer \& Zhu, 2013). Many professors teaching MOOCs think students do not deserve course credit for completing a MOOC (Kolowich, 2013). The concerns for course credit are mainly about course quality and the assessment of learning (Meyer \& Zhu, 2013). According to Lederman (2013), only five of Coursera's courses are approved for course credit by the American Council on Education. However, the acceptance of MOOCs for credit hours is growing. Currently, some MOOC providers charge fees for certificates and some have begun to offer credits. For example, the University of Washington offers students college credits for some of its courses, if they take them through Coursera, pay a fee, and complete the additional assessments (Long, 2012). The Colorado State University's Global Campus gives three credits for students who complete a free course offered by Udacity and pass a proctored test (Lewin, 2012; Skiba, 2012). Companies that offer MOOC platforms, such as Coursera, EdX, and Udacity, are growing (Skiba, 2012).

However, Porter (2013) argues that MOOCs is more like "learning tutorials" or "online interactive workshops" than "college courses." Does MOOCs have to be connected with credits? The answer remains unclear. Yuan, Powell, and Cetis (2013) argue that since most learners using MOOCs are people who already have a degree, it is not important whether a MOOC carries credit. This argument raises the debate about MOOCs and degrees. Daniel (2012) indicates what decides whether or not a student can obtain a degree is determined not by their mastery of the course, but by the admissions process to the university. So, he argues that the completion of a MOOC should not be connected with credits, which are towards a degree qualification.

\section{Ineffective assessments.}

Conducting effective assessments in a MOOC is a big challenge so far. On one hand, as a type of asynchronous online learning, MOOCs inheres security risks on the Internet. On the other hand, the number of available effective assessment methods is limited. The development of technology makes diverse cheating methods available for online assessments. According to a study completed by King, Guyette, and Piotrowski (2009), $73.6 \%$ of the students think it is easier to cheat in an online environment than in a conventional one. Methods of cheating with online assessments include using online communication and telecommunications, Internet surfing (Rogers, 2006), copying and pasting from online sources (Underwood \& Szabo, 2003), obtaining answer keys in an illegitimate way, taking the same assessment several times, and getting unauthorized assistance (Rowe, 2004). Other means of cheating on online tests include someone other than the actual student taking the online test and copying answers from elsewhere (Sasikumar, 2013). 
Therefore, MOOCs needs effective assessment methods that can perform user validation and prevent plagiarism (Cooper \& Sahami, 2013). For now, how to ensure the right person is taking a test with the correct materials remains a challenge. To mitigate this risk, some MOOCs providers offer proctored exams. Most of them are making plans to charge fees for such service (Lewin, 2013). For example, to validate students who are taking proctored exams, Coursera, edX, and Udacity tries to set-up partnerships with Pearson so MOOCs learners can take in-person examinations in Pearson testing centers (Parry, 2012; Udacity, 2012; Yuan, Powell, \& Cetis, 2013). Other than proctored exams, biometric authentication seems to be a solution for validating learners (Wang, Ge, Zhang, Chen, Xin, \&Li, 2013).

Because MOOCs relies heavily on computers, assessment methods that can be easily implemented by computers are used widely in MOOCs, including multiple choice questions, formulaic problems with correct answers, logical proofs, computer codes, and vocabulary activities (Cooper \& Sahami, 2013). However, none of these methods is good for assessing written work. So far two mechanisms have been adopted to evaluate essay assignments: (1) machine-based automated essay scoring (AES) and (2) calibrated peer review (CPR) (Balfour, 2013). But due to the limited capabilities of these two mechanisms, assessment methods implemented by computers are adopted widely in MOOCs.

\section{Complex copyright.}

Who is the owner that holds the copyrights for a MOOC course? The answer remains unclear because copyrights for a MOOC course are multifaceted. On one hand, copyrights for a MOOC course involve faculty, learners, universities, and MOOCs providers (Porter, 2013). Thus, MOOCs presents complex copyright issues that could challenge the relationships between a higher education institution, its faculty and learners, and MOOCs providers (Educause, 2013b). On the other hand, materials adopted in MOOCs are in diverse formats and they can be generated by either faculty or learners, or both. To date, a university can first offer a MOOC course with the best of intentions and then offer it via a MOOC provider. It is very likely that the MOOC provider makes profits by selling the MOOC course to other universities. Such a transaction raises the question: Should the university creating the MOOC course get rewards (Creelman, 2013)? In addition, MOOCs providers could violate the common institutional policy approach by establishing a proprietary claim on materials in its courses, licensing to the users the terms of access and use of those materials, and establishing its ownership claim of user-generated content (Educause, 2013b). Most materials in MOOCs, such as syllabuses, course policies, lecture videos, assignments, quizzes, class activities, and schedules, are developed by faculty (Porter, 2013). Therefore, according to the common institutional policy, copyrights for a MOOC course should belong to faculty who develop it, not MOOC providers. As such, Porter (2013) argues that faculty should be careful to understand the laws, policies, and contracts regarding copyrights when they develop MOOCs. However, learners who generate content for MOOCs should not be neglected. Some MOOCs require learners to submit 
assignments, evaluations, discussions, and projects. Once these materials are submitted, who owns them? Can MOOC providers use materials generated by learners in one MOOC course on other MOOC courses? These questions make it necessary to consider who owns materials in MOOC courses and who owns MOOC courses.

Besides the unclear ownership, MOOCs lacks its own copyright protection mode. Traditional copyright protection allows faculty and universities to reach copyright agreements regarding faculty's rights to their materials by following Creative Commons licenses, which regulate materials reuse and adaptation. The agreements work well for campus courses, in which faculty and universities are the main players of copyright protection. Compared with campus courses, MOOCs brings more stakeholders under copyright protection, such as learners and MOOCs providers. Obviously, the aforementioned agreements are not fit for MOOCs. Furthermore, Educause (2013b) indicates that fair-use exceptions to traditional copyright protection face challenges as well because MOOCs is open to learners around the world. As such, MOOCs needs its own copyright protection mode that involves faculty, universities, learners, and MOOCs providers.

\section{Limited hardware.}

In terms of hardware, MOOCs requires computers, headsets/speakers, microphones, and an Internet connection. Among the course contents, video lectures are the main components in MOOCs. Many course contents of MOOCs are delivered in video format via the Internet. To watch a high quality video, learners need broadband connections. However, not every learner has access to a fast Internet connection. A survey conducted by the Pew Internet \& American Life Project in 2012 shows that even in the U.S. only about $66 \%$ of adults have broadband access at home (Cooper \& Sahami, 2013), not to mention that many MOOCs learners are in developing countries and have limited access to the Internet. This hardware limitation needs to be overcome to make MOOCs accessible to more learners.

\section{Trends}

As a disruptive innovation, MOOCs transform higher education (Shirky, 2012). Cooper and Sahami (2013) note that MOOCs has the potential for making education accessible at a global level. Yuan, Powell, and Cetis (2013) argue that MOOCs will provide a powerful tool to make fundamental changes in the organization and delivery of higher education over the next decade. Daniel (2012) points out MOOCs will have an important impact in two ways: (1) improving teaching and (2) encouraging institutions to develop distinctive missions. MOOCs makes it possible for learners to obtain a complete college education from an elite institution online-free or at relatively low cost. This trend brings pressure for higher education institutions. Some colleges, especially the expensive, private schools that are not elite, will find it more difficult to attract students (Perez-Pena, 2012). Meanwhile, lower-tier colleges may have trouble convincing students their courses are worth the price (Lewin, 2012). 


\section{MOOCs and traditional higher education.}

Different from traditional higher education, MOOCs offers free, flexible courses to anyone who has Internet access. Will MOOCs replace traditional higher education? The answer is not clear yet. Many institutions choose to experiment with MOOCs as a way to improve their traditional model. For example, MIT and Harvard are conducting experiments with edX to learn how to educate their on-campus students more effectively (Bates, 2013). San J ose State University embeds MOOCs in traditional classes so students take MOOCs as homework and engage in deep problem-solving in the classroom (J arrett, 2012).

So far, traditional higher education is providing more and more online courses to meet learners' needs. Learners have the option to take online courses and obtain their degrees. Compared with MOOCs, these online courses are not free and learners will receive credits once they finish these online courses. The challenges MOOCs bring to traditional higher education begin from learners' choice between MOOCs and these online courses. When course qualities are the same, why do learners pay for taking online courses instead of taking free MOOCs? However, Clow (2013) argues that MOOCs alone cannot replace degrees or most other formal qualifications and the longterm value for universities is from things that cannot be cheaply duplicated through a MOOC. Therefore, instead of replacing traditional higher education, MOOCs is more likely to coexist with traditional higher education for a while. How long will the coexistence last? Will MOOCs replace traditional higher education ultimately? These questions provide a direction for future research.

\section{How can MOOCs be sustained?}

Although MOOCs are free for learners, developing MOOCs is not free. Belanger and Thornton (2013) indicate that Duke University's first MOOC on Bioelectricity cost over 600 hours to build and deliver. According to Stiehm (2013), an anthropology professor in Duke University estimated that he made 20 times more effort to complete the lessons for his MOOC than for his face-to-face course. However, the current business mode does not enable MOOCs to make money. How can MOOCs be sustained? Kolowich (2012) argues MOOCs will not be open for long and that many MOOCs will be developed as revenue-generating ventures. As such, will MOOCs be available for everyone? If not free, how can they compete with traditional higher education? A recent Insidetrack and ACE survey shows that faculty who have participated in teaching MOOCs and higher education administrators see MOOCs as a way to enhance the on-campus experience, not replace it (Inside Track, 2013). Therefore, the business mode that can sustain MOOCs is a topic for future research as well. 


\section{Limitations of this Study}

Blog mining is a novel method to synthesize related discussions in blogs to provide an in-depth review of MOOCs, and to identify future trends and challenges of MOOCs. It is well suited to MOOCs research, where existing academic studies are not adequate. However, blog posts can have an inherent bias. For example, the information on blogs is not peer-reviewed; authorship of some blog pages is either unclear or unknown; and some blog information might be posted for commercial purposes (He, 2013). Furthermore, the process of analyzing clusters and themes is subjective. To mitigate these limitations and improve research validity, blog mining should be combined with other research methods. Thus, the findings in this research should be validated by additional research with other methods.

\section{Conclusions}

MOOCs is a disruptive innovation and the current buzzword in higher education, but the discussions of MOOCs are disparate, fragmented, and distributed among different outlets. Systematic, extensively published research on MOOCs is not available. This paper adopts a novel method called blog mining to analyze MOOCs. Specifically, Google Blog Search and concept analysis and mapping software called Leximancer are applied in this study for data mining and result analysis.

The result of blog mining indicates that MOOCs benefits stakeholders, namely learners, faculty, universities, and providers. As more and more higher education institutions begin to provide MOOC courses, MOOCs seems to be a new direction for higher education. However, MOOCs face a lot of challenges, such as questionable course quality, high dropout rate, unavailable course credits, ineffective assessments, complex copyright, and limited hardware. These findings aid MOOCs providers and higher education institutions that might be interested in joining MOOCs to understand what is going on in this fast-moving field. MOOCs expanded fast recently because of the benefits it brings to stakeholders. But the aforementioned challenges hinder its further development. Future research needs to explore ways to overcome these challenges. In addition, this paper offers insights and tips for stakeholders so they can become knowledgeable about what drives the rapid expansion of MOOCs and the issues they might face if they choose to join MOOCs. Although MOOCs expanded fast recently, the position of MOOCs remains unclear. Will it coexist with traditional higher education or be a replacement? The answer is not available. A more urgent issue is how MOOCs can be sustained. Future research needs to explore the answers. 


\section{References}

Abdous, M., \&He, W. (2011), Using text mining to uncover students' technology-related problems in live video streaming. British J ournal of Educational Technology, 40(5), 40-49.

Balfour, S. P. (2013). Assessing writing in MOOCs: Automated essay scoring and calibrated peer review. Research \& Practice in Assessment, 8, 40-48.

Bali, M. (2013). 5 reasons teachers should dip into MOOCs for professional development. Retrieved from $\underline{\mathrm{htt}} \mathrm{p} / /$ moocnewsandreviews.com/5-reasonsteachers-should-dip-into-moocs-for-professional-development2/\#ixzz2ngE9J 9hC

Bates, T. (2012). What's right and what's wrong about coursera-style MOOCs. Retrieved from http:// www.tonybates.ca/ 2012/ 08/ 05/ whats-right-and-whats-wrongabout-coursera-style-moocs/

Belanger, V., \& Thornton, J . (2013). Bioelectricity: A quantitative approach-Duke University' first MOOC (Technical Report). Duke University, NC, USA.

Campbell, C., Pitt, L., Parent, M., \& Berthon, P. (2011). Understanding consumer conversations around ads in a Web 2.0 world. J ournal of Advertising, 40(1), 87-102.

Carey, K. (2013). Obama, Rubio agree on one thing: Technology could fix the higher ed mess. Retrieved from http:// tinyurl.com/ cogw2kh.s

Chau, M., \&Xu, J . (2012). Business intelligence in blogs: Understanding consumer interactions and communities. MIS Quarterly, 36(4), 1189-1216.

Clow, D. (2013). MOOCs and the funnel of participation. In Proceedings of the Third International Conference on Learning Analytics and Knowledge (pp. 185-189). ACM, New York.

Cooper, S., \&Sahami, M. (2013). Education reflections on Stanford's MOOCs: New possibilities in online education create new challenges. Communications of the ACM, 56(2), 28-30.

Creelman, A. (2013). MOOCs-copyright confusion. Retrived from http://acreelman.blogspot.com/2013/10/moocs-copyright-confusion.html

Cretchley, J ., Rooney, D., \& Gallois, C. (2010). Mapping a 40-year history with Leximancer: Themes and concepts in the J ournal of Cross-Cultural Psychology. J ournal of Cross-Cultural Psychology, 41(3), 318-328. 
Daniel, J . (2012). Making sense of MOOCs: Musing in a maze of myth, paradox and possibility. J ournal of Interactive Media in Education, 3.

deWaard, I., Abajian, S., Gallagher M.S., Hogue, R., Keskin, N., Koutropoulos, A., \& Rodriguez, O. (2011). Using mLearning and MOOCs to understand chaos, emergence, and complexity in education. The International Review of Research in Open and Distance Learning, 12(7), 95-115.

DiSalvio, P. (2012). Pardon the disruption: Innovation changes how we think about higher education. New England J ournal of Higher Education, 9/4/2012, 1.

Educause (2013). What is a MOOC? Retrieved from http:// www.educause.edu/library/massive-open-online-course-mooc

Educause (2013b). Copyright challenges in a MOOC environment. Retrieved from https:// net.educause.edu/ir/ library/pdf/ PUB9014.pdf

Furukawa, T., Ishizuka, M., Matsuo, Y., Ohmukai, I., \& Uchiyama, K. (2007). Analyzing reading behavior by blog mining. In Proceedings of the National Conference on Artificial Intelligence (Vol. 22, No. 2, pp. 1353). Menlo Park, CA; Cambridge, MA; London; AAAI Press; MIT Press; 1999.

Gardner, L., \&Young, J . (2013). California's move toward MOOCs sends shock waves, but key questions remain unanswered. The Chronicle of Higher Education.

He, W. (2013). A survey of security risks of mobile social media through blog mining and an extensive literature search. Information Management \& Computer Security, 21(5), 381-400.

Hill, P. (2012). Four barriers that MOOCs must overcome to build a sustainable model.

Retrieved from http:// mfeldstein.com/four-barriers-that-moocs-mustovercome-to-become-sustainable-model

Inside Track (2013). To MOOC or not to MOOC: Strategic lessons from the pioneers. Retrieved from http:// www.insidetrack.com/mooc-mooc-strategic-lessonspioneers/

J ackson, K., \& Trochim, W.K.M. (2002), Concept mapping as an alternative approach for the analysis of open-ended survey responses. Organizational Research Methods, 5(4), 307-336.

J arrett, J . (2012). What are MOOCs and why are education leaders interested in them? Retrieved from http:/ / www.huffingtonpost.com/ impatient-optimists/ what-aremoocs-and-why-ar_b_2123399.html 
King, C. G., Guyette, R. W., \& Piotrowski, C. (2009). Online exams and cheating: An empirical analysis of business students' views. The J ournal of Educators Online, 6(1), 1-11.

Kolowich, S. (2012). MOOCs for credit. Inside Higher Education. Retrieved from http:// www.insidehighered.com/news/2012/10/29/ coursera-strikes-mooclicensing-deal-antioch-university

Kolowich, S. (2013). The professors who make the MOOCs. Chronicle of Higher Education. Retrieved from http:// chronicle.com/article/The-ProfessorsBehind-the-MOOC/ 137905/ \#id=overview

Kop, R., \&Hill, A. (2008). Connectivism: Learning theory of the future or vestige of the past? The International Review of Research in Open and Distance Learning, $9(3)$.

Lederman, D. (2013). Expanding pathways to MOOC credit. Inside Higher Education. Retrieved from http:/ / www.insidehighered.com/news/ 2013/ 02/ 07/ ace-deems5-massive-open-courses-worthy-credit

Leximancer (2010). Leximancer white paper. Brisbane, Australia: Leximancer. Retrieved from https:// www.leximancer.com/lmedia/Leximancer_White_Paper_2010.pdf

Leximancer (2011). Leximancer manual: Version 4. Brisbane, Australia: Leximancer. Retrieved from https:// www.leximancer.com/lp/ 4.00.20L1173952/m/doc/LeximancerManual. pdf

Lewin, T. (2012, November 19). College of future could become one, come all. The New York Times.

Lewin, T. (2013, February 20). Universities abroad join partnerships on the Web. The New York Times.

Long, K. (2012, J uly 18). UW to offer fee-based courses through Coursesea. The Seattle Times.

Martin, N., \& Rice, J . (2011). Cybercrime: Understanding and addressing the concerns of stakeholders. Computers \& Security, 30(8), 803-814.

McAulay, A., Stewart, B., \& Siemens, G. (2010). The MOOC model for digital practice. University of Prince Edward Island. Retrieved from http:// www.elearnspace.org/Articles/MOOC_Final.pdf 
Meyer, J .P., \&Zhu, S. (2013). Fair and equitable measurement of student learning in MOOCs: An introduction to item response theory, scale linking, and score equating. Research \& Practice in Assessment, 8(1), 26-39.

Mioduser, D., Nachmias, R., \& Forkush-Baruch, A. (2008). New literacies for the knowledge society. In J . Voogt \& G. A. Knezek (Eds.), International handbook of information technology in primacy and secondary education (pp.23-42). New York; London: Springer.

New Media Horizon and EDUCAUSE (2013). NMC Horizon report: 2013 higher education edition. New Media Consortium.

Pappano, L. (2012, November 2). The year of the MOOC. The New York Times, 2(12).

Parry, M. (2012, September 6). EdX offfres proctored exams for open online course. The Chronicle of Higher Education.

Perez-Pena, R. (2012, J uly 17). Top universities test the online appeal of free. The New York Times.

Perez-Pena, R. (2012). Top universities test the online appeal of free. The New York Times. Retrieved from http:// www. nytimes. com/2012/ 07/ 18/ education/topuniversities-test-theonline-appeal-of-free

Porter, J . E. (2013). MOOCS, “Courses”, and the question for faculty and student copyrights. The CCCC-IP Annual: Top Intellectual Property Developments of 2012.

Raza, K. (2013). What's a mooc and why you should know and care! Retrieved from http:// socialmediatoday.com/khalidraza9/1413716/ what-mooc

Reich, J . (2012). Summzrizing all MOOCs in one slide: Market, open and dewey. Retrieved from http://blogs.edweek.org/edweek/ edtechresearcher/2012/05/all_moocs_explai ned_market_open_and_dewey.html

Rodriguez. C. O. (2013). MOOCs and the Al-Standard like courses: Two successful and distinct course formats for massive open online courses. The European J ournal of Open, Distance and E-Learning. Retrieved from http:// www.eurodl.org/ ?article $=516$

Rogers, C. F. (2006). Faculty perceptions about e-cheating during online testing, J ournal of Computing Sciences in Colleges, 22(2), 206-212.

Rowe, N. C. (2004). Cheating in online student assessment: Beyond plagiarism. Online J ournal of Distance Learning Administration, 7(2). 
Rubin, V. L., Burkel, J ., \& Quan-Haase, A. (2011). Facets of serendipity in everyday chance encounters: A grounded theory approach to blog analysis. Information Research: an International Electronic J ournal, 6(3).

Sandeen, C. (2013). Assessment's place in the new MOOC world. Research \& Practice in Assessment, 8(1), 5-12.

Schrire, S., \& Levy, D. (2012). Troubleshooting MOOCs: The case of massive open online course at a college of education. In Proceedings of the World Conference on Educational Multimedia, Hypermedia and Telecommunications (pp. 761766).

Sasikumar, M. (2013). E-learning: Opportunity and challenges. Retrieved from http:// www.cdacmumbai.in/design/ corporate_site/ override/ pdf-doc/elearning.pdf

Shirky, C. (2012). Napster, Udacity and the academy [Web log post].

Siemens, G. (2012). MOOCs are really a platform. Elearnspace. Retrieved from http:// elearnspace.org/ blog/2012/07/25/ moocs-are-really-a-platform/

Siemens, G., \&Downes, S. (2008). Connectivism \& connected knowledge: CCK08, CCK09. Retrieved from http:// ltc.umanitoba.ca/connectivism/

Skiba, D. (2012). Disruption in higher education: massively open online courses (MOOCs). Nursing Education Perspectives, 33(6), 416-417.

Smith, A. E., \& Humphreys, M.S. (2006). Evaluation of unsupervised semantic mapping of natural language with Leximancer concept mapping. Behavior Research Methods, 38(2), 262-279.

Stiehm, C. (2013). Faculty members share experiences with MOOCs. Retrieved from http:// www.dukechronicle.com/ articles/2013/ 09/27/ faculty-members-shareexperiences-moocs

Thrift, N. (2013). To MOOC or not to MOOC. Chronicle of Higher Education. Retrieved from http:// chronicle.come/ blogs/ worldwise/ to-mooc-or-not-to-mooc/31721

Udacity blog (2012). Udacity in partnership with Pearson VUE announces testing centers. Retrieved from http:// blog.udacity.com/2012/ 06/ udacity-inpartnership-with-pearson-vue.html

Ulicny, B., Baclawski, K., \& Magnus, A. (2007). New metrics for blog mining. In Defense and Security Symposium (pp. 657001-657001). International Society for Optics and Photonics. 
Underwood, J ., \& Szabo, A. (2003). Academic offences and e-learning: Individual propensities in cheating. British J ournal of Educational Technology, 34(4), 467-477.

Voss, B. D. (2013). Massive open online courses (MOOCs): A primer for university and college board members. Retrived from http://agb.org/sites/agb.org/files/report_2013_MOOCs.pdf

Wang, F., Ge, B., Zhang, L., Chen, Y., Xin, Y., \& Li, X. (2013). A system framework of security management in enterprise systems. Systems Research and Behavioral Science.

Watson, M., Smith, A., \&Watter, S. (2005). Leximancer concept mapping of patient case studies. In Knowledge-based intelligent information and engineering systems (pp. 1232-1238). Springer Berlin Heidelberg.

Yuan, L., Powell, S., \& Cetis, J . (2013). MOOCs and open education: Implications for higher education. Retrieved from http:// www.smarthighered.com/ wpcontent/uploads/2013/03/MOOCs-and-Open-Education.pdf

\section{Athabasca University $\mathbf{a}$}

(ㄷ) $(1)$ 